\title{
Prognosis of PD-L1 in human breast cancer: protocol for a systematic review and meta- analysis
}

Isnard Elman Litvin ${ }^{1,2^{*}}$, Machline Paim Paganella ${ }^{3}$, Eliana Marcia Wendland ${ }^{4}$ and Adriana Vial Roehe ${ }^{1}$

\begin{abstract}
Background: Breast cancer is one of the most common malignancies in women worldwide, and one of the leading causes of cancer-related death. Programmed cell death 1 (PD-1) and its ligand (PD-L1) are key physiologic suppressors of the cytotoxic immune reaction. Some authors advocate that PD-L1 expression may help in breast cancer prognosis.

Methods: We will conduct a systematic review of observational or interventional studies evaluating the prognostic ability of PD-L1 expression levels in predicting positive clinical outcomes in Human Breast Cancer. A sensitive search strategy will be employed in MEDLINE, EMBASE, LILACS, The Grey Literature Report, OpenGrey, OAlster, and Cochrane CENTRAL. Two reviewers will independently screen all identified references for eligibility and extract data. The outcomes evaluated will be Overall Survival, Breast Cancer-specific Survival, Disease-free Survival, Recurrencefree Survival, Positive Lymph Node, and Distant Metastasis. The outcomes will be extracted directly from the studies, if available. Methodological quality and bias of included studies will be assessed using a standardized checklist and overall quality of evidence will be assessed through the Grading of Recommendations Assessment, Development and Evaluation (GRADE) approach. If meta-analysis is possible, the measures of association will be calculated using bivariate random-effects models. Statistical heterogeneity will be evaluated with $P^{2}$ statistics and explored through sensitivity analysis.
\end{abstract}

Discussion: Immunomodulation seems to be a promising strategy in solid tumors. Breast cancer is the most common malignancies in women worldwide, and one of the leading causes of cancer death. PD-1 and PD-L1 are key physiologic suppressors of the cytotoxic immune reaction.

Trial registration: Systematic review registration: CRD42019121118 (PROSPERO)

Keywords: PD-L1, Human Breast Cancer, Systematic Review, Meta-analysis, Protocol

\section{Background}

Breast cancer $(\mathrm{BC})$ is one of the most common malignancies in women worldwide, and one of the leading causes of cancer death $[1,2]$. In $\mathrm{BC}$, the bulk of evidence

\footnotetext{
*Correspondence: ielitvin@ucs.br

'Graduate Program in Pathology, Federal University of Health Sciences of Porto Alegre, Porto Alegre, RS, Brazil

${ }^{2}$ School of Medicine, University of Caxias do Sul -UCS, Caxias do Sul, RS, Brazil

Full list of author information is available at the end of the article
}

showed that immune cells infiltration presented in the tumor, especially tumor-infiltrating lymphocytes (TILs), were associated with clinical outcomes in some malignant tumors [2-6]. TILs evaluated in primary BC may convey prognostic information [7], although their precise use remains unclear [8].

The programmed cell death-1 receptor (PD-1) is an immune checkpoint inhibitor that is expressed on the surface of immune effectors cells. It is activated mainly

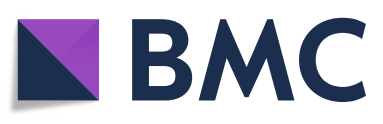

(C) The Author(s). 2020 Open Access This article is licensed under a Creative Commons Attribution 4.0 International License, which permits use, sharing, adaptation, distribution and reproduction in any medium or format, as long as you give appropriate credit to the original author(s) and the source, provide a link to the Creative Commons licence, and indicate if changes were made. The images or other third party material in this article are included in the article's Creative Commons licence, unless indicated otherwise in a credit line to the material. If material is not included in the article's Creative Commons licence and your intended use is not permitted by statutory regulation or exceeds the permitted use, you will need to obtain permission directly from the copyright holder. To view a copy of this licence, visit http://creativecommons.org/licenses/by/4.0/. The Creative Commons Public Domain Dedication waiver (http://creativecommons.org/publicdomain/zero/1.0/) applies to the data made available in this article, unless otherwise stated in a credit line to the data. 
by its ligand (PD-L1) which can be expressed by all human cells. The PD-1/PD-L1 pathway plays a subtle role in maintaining peripheral T-lymphocyte tolerance and regulating inflammation [9].

PD-1 and PD-L1 are key physiologic suppressors of the cytotoxic immune reaction. Results from preclinical studies support the idea that inhibition of PD-L1 and PD-1 axis in the tumor microenvironment may promote tumor regression, and in clinical trials, various agents targeting PD-1 or PD-L1 have demonstrated robust response rates in a variety of tumor types [10-16]. Limited data have been reported on the expression of PD-L1 in tumor cells and/or immune cells in breast cancer, but preliminary reports are divergent [16-20]. Few studies have evaluated the expression of the programmed cell death-1 and its ligand-1 (PD-L1) in breast cancer [21].

Hou et al. evaluated PD-L1 and a set of other relevant immune markers in relation to their association with clinical outcome in a series of HER2-positive BC cases. They suggest that cytotoxic immune reaction mediated by CD8-positive $\mathrm{T}$ cells and PD-L1 expression may predict a better outcome in patients with HER2-positive BC managed with conventional chemotherapy and HER2blocking therapy [16].

The purpose of this protocol of systematic review and meta-analysis is to assess the prognostic value of PD-L1 in Human Breast Cancer.

\section{Methods}

\section{Protocol and registration}

The protocol for this review was defined a priori and registered online in the PROSPERO international prospective register of systematic reviews (CRD42019121118). The methodological approach to evidence searching and synthesis, described in this protocol, will follow the Preferred Reporting Items for Systematic Review and Meta-Analysis Protocols (PRISMA-P) recommendations [22] (see Additional file 1) and MOOSE Guidelines for Meta-Analyses and Systematic Reviews of Observational Studies [23].

\section{PECO question}

For systematic review and meta-analysis of studies on risk factors and prognosis, the acronym PECO is used, which corresponds to the areas $\mathrm{P}$ (population), E (exposure), C (comparison) and O (outcome). The STEEP system was considered as a standardized definition system of the outcomes [24]. The formulated PECO question is: What is the prognostic significance of programmed cell death 1 (PD-L1) expression in breast cancer?

The definitions for the acronym PECO for this systematic review are the following:
- Population: women aged 18 years or more with breast cancer pathologically confirmed of any type

- Exposure: PD-L1-positive based on immunohistochemistry (IHC)

- Comparison: PD-L1-negative based on IHC

- Outcomes (and its definitions):

Overall survival (OS): death from breast cancer, death from a non-breast cancer cause, and death from unknown cause

$\bigcirc$ Progression-free survival (PFS)

BC-specific survival (BCSS)

$\bigcirc$ Disease-free survival (DFS): invasive ipsilateral breast tumor recurrence, local/regional invasive recurrence, distant recurrence, death from breast cancer, death from a non-breast cancer cause, death from an unknown cause, invasive contralateral breast cancer, and second primary invasive cancer (non-breast)

Recurrence-free survival (RFS): invasive ipsilateral breast tumor recurrence, local/regional invasive recurrence, distant recurrence, death from breast cancer, death from a non-breast cancer cause, and death from an unknown cause

Positive lymph node (PLN)

Distant metastasis (DM)

$\bigcirc$ Distant disease-free survival (DDFS): distant recurrence, death from breast cancer, death from a non-breast cancer cause, death from an unknown cause, second primary invasive cancer (non-breast) $\bigcirc$ Pathological response after neoadjuvant chemotherapy

\section{Criteria for considering studies for this review}

In the review, we will include any observational (cohort) or intervention studies (randomized controlled trials) which evaluate the prognostic ability of PD-L1 expression using IHC (using any method and any type of PDL1 clone) in women with breast cancer. We will include studies that evaluate PD-L1 positivity with different cutoffs according to various scoring systems including Histo-score system (H-score), PD-L1 expression in tumor/normal breast samples ( $\mathrm{T} / \mathrm{NB}$ ratio), 4-point scale, Allred score, or Immunoscore (staining intensity and percentage of PD-L1 positive tumor cells). When studies include both women with and without breast cancer, only women with the target disease will be evaluated. Articles will be excluded from the analyses based on the following criteria: PD-L1 expressed only on other cells (e.g., immune cell and stromal cell), not tumor cell; non-human experiments, case reports, case series, casecontrol, animal testing, narrative reviews, duplicate publication, meeting abstracts, and expert opinions. Studies that are published as abstract only and whose detailed 
information cannot be obtained from the authors will be excluded.

\section{Search methods for identification of studies}

The keywords and Medical Subject Headings related to PD-1, PD-L1, and Human Breast Cancer will be used alone or in combination (and with synonyms and closely related words) in order to retrieve relevant articles.

We will search in Excerpta Medica Database (EMBASE), Centro Latinoamericano y del Caribe de Información en Ciencias de la Salud (LILACS), Medical Literature Analysis and Retrieval System Online (MEDLINE), Cochrane Central Register of Controlled Trials (CENTRAL), and Web of Science. We will also screen reference lists of relevant studies and reviews for additional articles and will search websites of Grey Literature such as The Grey Literature Report, OpenGrey and Open Archives Initiative (OAIster). If necessary (unclear data, missing data, and extractable data). The search strategies developed for each database are shown on Additional file 2. There will be no language or publication year restriction. The PRISMA Flow Diagram will be used to depict the flow of information through the different phases of a systematic review (see Additional file $3)$.

\section{Study selection process}

Potentially eligible studies will be screened for inclusion eligibility independently by two review authors (IEL and AVR) based on their title, abstract, and full text. A third author (MPP) will adjudicate any discrepancies. Reasons for excluding full-text studies will be documented.

\section{Data collection}

From eligible studies, we will extract bibliographical and study description data (e.g., title, author, country, study design, language of publication, year of publication, sample size, number of centers), patient characteristics (e.g., total number and number in comparison groups, age), and data related to breast cancer and prognosis. Data collection will be performed, independently and in duplicates by two reviewers (IEL, AVR), using predefined data fields (Table 1). Table 1 will be pilot-tested to assess for usability and any amendments will be performed if required. We will attempt to establish contact with the corresponding authors for missing data.

\section{Risk of bias assessment}

Quality In Prognosis Studies (QUIPS) tool will be used to assess the risk of bias in prognostic factor studies [25]. The QUIPS tool rates six bias domains: study participation, study attrition, prognostic factor measurement, outcome measurement, study confounding, and statistical analysis and reporting, as having a high, moderate, or low risk of bias [26]. The Grading of Recommendations Assessment, Development, and Evaluation (GRADE) will be used to rate the quality of the body of evidence retrieved $[27,28]$.

\section{Statistical analysis}

If identified as possible (the studies retrieved have quantitative data reported that can be combined), the extracted data will be aggregated into a meta-analysis by "R" Software. Hazard ratios (HRs) and 95\% confidence intervals will be pooled to measure the time to event relationship (between the potential prognostic factor and tumor recurrence). Data derived from the multivariate analysis will be used as default, but when absent, univariate values will be used. A combination of adjusted and unadjusted hazard ratio estimates for the association between PD-L1 expression and breast cancer will be managed by using the patient-level correlation as an approximation for the within-study correlation [29]. Results from interventional and from observational studies will be pooled separately, in a sensitivity analysis. Standard errors will be calculated from confidence intervals and the individual study associations [30-33]. The measure of association estimates will be weighted and combined using the generic inverse variance and random effect model.

To allow the readers to visualize any general trends or mixed findings across the studies, we intend (if possible) to present a Forest Plot with the individual study estimates and confidence intervals.

Publication bias will be assessed by visual inspection of the funnel plot or Egger's test, according to the number of articles included. Heterogeneity will be assessed by the Cochran $\mathrm{Q}$ and $I^{2}$ statistics. When more than one threshold is available, all data will be recorded. Sensitivity analysis will be conducted to assess the impact of including studies with $20 \%$ or more of missing data and also to study the impact of the different study designs. The impact of study design (cohort versus clinical trials) will be evaluated in a sensitivity analysis. Subgroup analysis will be performed, if possible regarding the KI-67 index, Tumor Size and Type, Nottingham Grade, ER/PR (Estrogen Receptor/Progesterone Receptor) Status and IHC method/clone type. All statistical tests will be 2sided, and statistical significance will be defined as $p<$ 0.05 .

\section{Discussion}

High level of immune infiltration in the primary tumor, measured by the number of TILs or immune gene expression signatures, has been associated with longer survival and response to neoadjuvant chemotherapy in triple-negative and HER2 positive breast cancers (not in luminal A breast cancers) [34-43]. A strong lymphocytic 


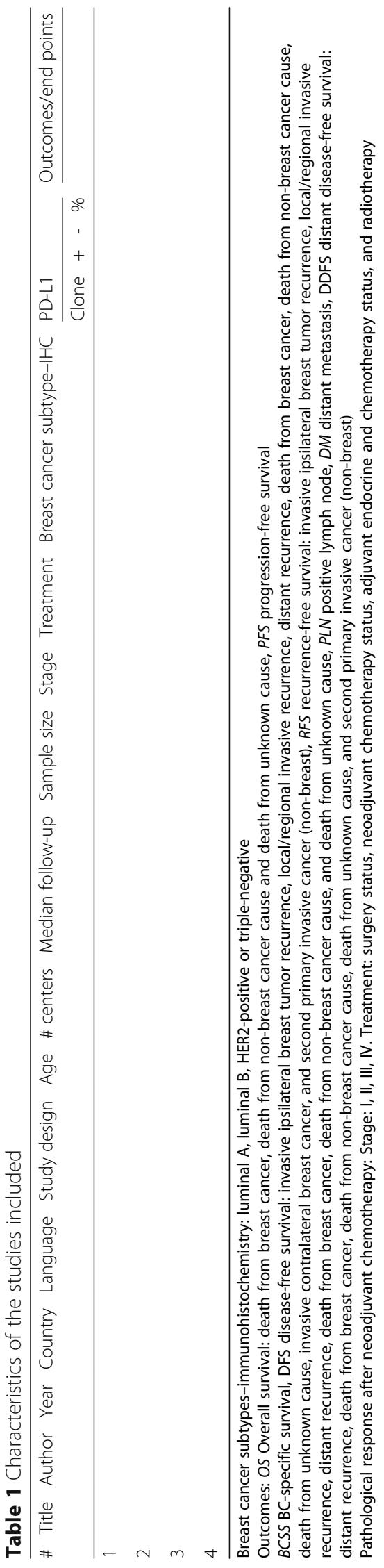


infiltration in the residual tumor after neoadjuvant chemotherapy has also been associated with longer survival. The immune microenvironment influences the efficacy of chemotherapy and radiotherapy; these treatments cause an immunogenic death of the malignant cells and/or somatic mutations leading to neoantigens that elicit an adaptive immune response which will clear or keep the escaping tumor cells dormant $[43,44]$.

PD-1/PD-L1 inhibitors have shown promising activity in the first clinical trials in breast cancer, and some trials are testing their efficacy and safety in the metastatic and neoadjuvant setting $[43,45,46]$.

Immunomodulation seems to be a promising strategy in solid tumors where the PD-1/PD-L1 inhibitory pathway can be misused to silence the immune system by increasing the expression of PD-L1 on the tumor cell surface. PD-L1 expression has been associated with: large tumor size, high grade, high proliferation, estrogen receptornegative status, and HER2-positive status, and it is inversely correlated with survival in breast cancer $[9,18,47]$. According to Mittendorf et al., PD-L1 is expressed in 20\% of triple-negative breast cancers (TNBCs) [20].

Muenst et al. published the first study to demonstrate that PD-L1 expression is an independent negative prognostic factor in human breast cancer. They conducted an IHC study using a tissue microarray encompassing 650 evaluable formalin-fixed breast cancer sample cases with detailed clinical annotation and outcomes data. PDL1 was expressed in 152 (23.4\%) of the 650 breast cancer specimens. Expression was significantly associated with age, tumor size, AJCC (American Joint Committee on Cancer) primary tumor classification, tumor grade, lymph node status, absence of ER expression, and high Ki-67 expression. In univariate analysis, PD-L1 expression was associated with a significantly worse overall survivor [48].

Sabatier et al. retrospectively analyzed PD-L1 mRNA expression in 45 breast cancer cell lines and profile 5454 breast cancers using DNA microarrays. They found that compared to normal breast samples, PDL1 expression was upregulated in $20 \%$ of clinical samples and $38 \%$ of basal tumors and concluded that PD-L1 upregulation was associated with increased $\mathrm{T}$ cell cytotoxic immune response. In this aggressive subtype, upregulation was associated with better survival and response to chemotherapy [18].

A previous meta-analysis performed by Wang et al. supported the notion that high PD-L1 expression in breast cancer is correlated with poor prognosis. Their study was restricted to English publications and included PD-L1 assessed by mRNA level and IHC [49].

Many issues remain to be answered, such as the identification of biomarkers able to predict for a clinical benefit of PD-L1 inhibitors. This systematic review can help to clarify the prognostic significance of PD-L1 expression in breast cancer.

\section{Supplementary information}

Supplementary information accompanies this paper at https://doi.org/10. 1186/s13643-020-01306-9.

Additional file 1:. PRISMA-P.

Additional file 2:. Database searches.

Additional file 3:. PRISMA Flow Diagram.

\section{Abbreviations}

AJCC: American Joint Committee on Cancer; BC: Breast cancer; BCSS: Breast cancer-specific survival; CENTRAL: Cochrane Central Register of Controlled Trials; DDFS: Distant disease-free survival; DFS: Disease-free survival; DM: Distant metastasis; EMBASE: Excerpta Medica Database; ER: Estrogen receptor; GRADE: Grading of Recommendations Assessment, Development and Evaluation; HR: Hazard ratio; IHC: Immunohistochemistry; LILACS: Centro Latinoamericano y del Caribe de Información en Ciencias de la Salud; MEDLINE: Medical Literature Analysis and Retrieval System Online; MOOSE: Meta-analyses Of Observational Studies in Epidemiology; OAlster: Open Archives Initiative; OS: Overall survival; PD-1: Programmed cell death-1 receptor; PD-L1: Programmed cell death-1 receptor ligand 1;

PECO: Population, Exposure, Comparison, Outcome; PFS: Progression-free survival; PLN: Positive lymph node; PR: Progesterone receptor; PRISMA: Preferred Reporting Items for Systematic Review and Meta-Analysis; PRISMA-P: Preferred Reporting Items for Systematic Review and MetaAnalysis Protocols; QUIPS: Quality In Prognosis Studies; RFS: Recurrence-free survival; TILs: Tumor-infiltrating lymphocytes

\section{Acknowledgements \\ Not applicable. \\ Ethics approval and consent to participate}

\section{Not applicable}

Not applicable.

\section{Authors' contributions}

IEL, AVR, and MPP contributed to the conception of the study protocol and search strategy. IEL and EMW designed the statistical analysis plan. The manuscript of the protocol was drafted by IEL and was critically revised by MPP. MPP and IEL registered the protocol with the PROSPERO database. AVR reviewed the manuscript. All authors have read and approved the publication of the protocol.

\section{Funding}

This protocol has not received any kind of grant or funding (external or not).

Availability of data and materials

Not applicable.

Consent for publication

This manuscript does not contain any individual person's data in any form.

Competing interests

The authors declare that they have no competing interests.

\section{Author details}

${ }^{1}$ Graduate Program in Pathology, Federal University of Health Sciences of Porto Alegre, Porto Alegre, RS, Brazil. ${ }^{2}$ School of Medicine, University of Caxias do Sul -UCS, Caxias do Sul, RS, Brazil. ${ }^{3}$ Instituto de Pesquisas em Saúde (IPS), University of Caxias do Sul-UCS, Caxias do Sul, RS, Brazil. ${ }^{4}$ Federal University of Health Sciences of Porto Alegre, Community Health Department, Porto Alegre, RS, Brazil. 
Received: 3 May 2019 Accepted: 20 February 2020

Published online: 26 March 2020

\section{References}

1. Andre F, Dieci M V., Dubsky P, Sotiriou C, Curigliano G, Denkert C, et al. Molecular pathways: involvement of immune pathways in the therapeutic response and outcome in breast cancer. Clin Cancer Res. 2013 19(1):28-33. Available from: http://www.ncbi.nlm.nih.gov/pubmed/23258741.

2. Mao Y, Qu Q, Chen X, Huang O, Wu J, Shen K. The Prognostic Value of Tumor-Infiltrating Lymphocytes in Breast Cancer: A Systematic Review and Meta-Analysis. PLoS One. 2016:11(4):e0152500. Available from: http://www. ncbi.nlm.nih.gov/pubmed/27073890.

3. Loi S, Sirtaine N, Piette F, Salgado R, Viale G, Van Eenoo F, et al. Prognostic and predictive value of tumor-infiltrating lymphocytes in a phase III randomized adjuvant breast cancer trial in node-positive breast cancer comparing the addition of docetaxel to doxorubicin with doxorubicinbased chemotherapy: BIG 02-98. J Clin Oncol. 2013 31(7):860-867. Available from: http://www.ncbi.n/m.nih.gov/pubmed/23341518.

4. Mahmoud SMA, Paish EC, Powe DG, Macmillan RD, Grainge MJ, Lee AHS, et al. Tumor-infiltrating CD8+ lymphocytes predict clinical outcome in breast cancer. J Clin Oncol. 2011;29(15):1949-1955. Available from: http:// www.ncbi.n/m.nih.gov/pubmed/21483002.

5. Ménard S, Tomasic G, Casalini P, Balsari A, Pilotti S, Cascinelli N, et al. Lymphoid infiltration as a prognostic variable for early-onset breast carcinomas. Clin Cancer Res. 1997 ;3(5):817-819. Available from: http://www. ncbi.nlm.nih.gov/pubmed/9815754

6. Mohammed ZMA, Going JJ, Edwards J, Elsberger B, Doughty JC, McMillan DC. The relationship between components of tumour inflammatory cell infiltrate and clinicopathological factors and survival in patients with primary operable invasive ductal breast cancer. Br J Cancer 2012;107(5):864873. Available from: https://doi.org/10.1038/bjc.2012.347.

7. Dieci MV, Tsvetkova V, Orvieto E, Piacentini F, Ficarra G, Griguolo G, et al. Immune characterization of breast cancer metastases: prognostic implications. Breast Cancer Res. 2018;20(1):62. Available from: http://www. ncbi.nlm.nih.gov/pubmed/29929548.

8. Hida Al, Sagara Y, Yotsumoto D, Kanemitsu S, Kawano J, Baba S, et al. Prognostic and predictive impacts of tumor-infiltrating lymphocytes differ between Triple-negative and HER2-positive breast cancers treated with standard systemic therapies. Breast Cancer Res Treat. 2016:158(1):1-9. Available from: http://www.ncbi.nlm.nih.gov/pubmed/27260189.

9. Schütz F, Stefanovic S, Mayer L, von Au A, Domschke C, Sohn C. PD-1/PD-L1 Pathway in Breast Cancer. Oncol Res Treat. 2017;40(5):294-297. Available from: http://www.ncbi.n/m.nih.gov/pubmed/28346916.

10. Topalian SL, Hodi FS, Brahmer JR, Gettinger SN, Smith DC, McDermott DF, et al. Safety, activity, and immune correlates of anti-PD-1 antibody in cancer. N Engl J Med. 2012;366(26):2443-2454. Available from: http://www.ncbi.nlm. nih.gov/pubmed/22658127.

11. Pardoll DM. The blockade of immune checkpoints in cancer immunotherapy. Nat Rev Cancer [Internet]. 2012;12(4):252-264. Available from: https://doi.org/10.1038/nrc3239.

12. Rizvi NA, Hellmann MD, Snyder A, Kvistborg P, Makarov V, Havel JJ, et al. Cancer immunology. Mutational landscape determines sensitivity to PD-1 blockade in non-small cell lung cancer. Science. $2015 ; 348(6230): 124-128$. Available from: http://www.ncbi.nlm.nih.gov/pubmed/25765070.

13. Ribas A. Adaptive Immune Resistance: How Cancer Protects from Immune Attack. Cancer Discov. 2015;5(9):915-919. Available from: http://www.ncbi. nlm.nih.gov/pubmed/26272491.

14. Taube JM, Klein A, Brahmer JR, Xu H, Pan X, Kim JH, et al. Association of PD1, PD-1 ligands, and other features of the tumor immune microenvironment with response to anti-PD-1 therapy. Clin Cancer Res 2014 20(19):5064-5074. Available from: http://www.ncbi.nlm.nih.gov/pubmed/24 714771.

15. Vaughn $C P$, Zobell SD, Furtado $L$ V , Baker $C L$, Samowitz WS. Frequency of KRAS, BRAF, and NRAS mutations in colorectal cancer. Genes Chromosomes Cancer. $2011 ; 50(5): 307-312$. Available from: http://www.ncbi.nlm.nih.gov/ pubmed/21305640.

16. Hou Y, Nitta H, Wei L, Banks PM, Lustberg M, Wesolowski R, et al. PD-L1 expression and CD8-positive T cells are associated with favorable survival in HER2-positive invasive breast cancer. Breast J. 2018 ;24(6):911-919. Available from: http://www.ncbi.n/m.nih.gov/pubmed/30230111.
17. Baptista MZ, Sarian LO, Derchain SFM, Pinto GA, Vassallo J. Prognostic significance of PD-L1 and PD-L2 in breast cancer. Hum Pathol. $2016 ; 47(1)$ 78-84. Available from: http://www.ncbi.nlm.nih.gov/pubmed/26541326.

18. Sabatier R, Finetti $P$, Mamessier $E$, Adelaide J, Chaffanet M, Ali HR, et al. Prognostic and predictive value of PDL1 expression in breast cancer. Oncotarget. 2015;6(7):5449-5464. Available from: http://www.ncbi.nlm.nih. gov/pubmed/25669979.

19. Beckers RK, Selinger Cl, Vilain R, Madore J, Wilmott JS, Harvey K, et al. Programmed death ligand 1 expression in triple-negative breast cancer is associated with tumour-infiltrating lymphocytes and improved outcome. Histopathology. 2016 ;69(1):25-34. Available from: http://www.ncbi.nlm.nih. gov/pubmed/26588661

20. Mittendorf EA, Philips A V, Meric-Bernstam F, Qiao N, Wu Y, Harrington S, et al. PD-L1 expression in triple-negative breast cancer. Cancer Immunol Res [Internet]. 2014 ;2(4):361-370. Available from: http://www.ncbi.nlm.nih.gov/ pubmed/24764583.

21. Tawfik O, Kimler BF, Karnik T, Shehata P. Clinicopathological correlation of PD-L1 expression in primary and metastatic breast cancer and infiltrating immune cells. Hum Pathol [Internet]. 2018:80:170-178. Available from: http://www.ncbi.nlm.nih.gov/pubmed/29936058.

22. PRISMA. 2009 Checklist PRISMA 2009 Checklist, vol. 2; 2009. p. 1-2.

23. Stroup DF, Berlin JA, Morton SC, Olkin I, Williamson GD, Rennie D, et al. Meta-analysis of observational studies in epidemiology: a proposal for reporting. Meta-analysis Of Observational Studies in Epidemiology (MOOSE) group. JAMA [Internet]. $2000 ; 283(15): 2008-2012$. Available from: http:// www.ncbi.nlm.nih.gov/pubmed/10789670.

24. Hudis CA, Barlow WE, Costantino JP, Gray RJ, Pritchard Kl, Chapman J-AW, et al. Proposal for standardized definitions for efficacy end points in adjuvant breast cancer trials: the STEEP system. J Clin Oncol. 2007 25(15): 2127-2132. Available from: http://www.ncbi.nlm.nih.gov/pubmed/17513820.

25. Hayden JA, Côté $P$, Bombardier $C$. Evaluation of the quality of prognosis studies in systematic reviews. Ann Intern Med [Internet]. 2006 ;144(6):427437. Available from: http://www.ncbi.nlm.nih.gov/pubmed/16549855.

26. Hayden JA, van der Windt DA, Cartwright JL, Côté P, Bombardier C. Assessing bias in studies of prognostic factors. Ann Intern Med [Internet]. 2013158(4):280-286. Available from: http://www.ncbi.n/m.nih.gov/ pubmed/23420236.

27. Guyatt G, Oxman AD, Akl EA, Kunz R, Vist G, Brozek J, et al. GRADE guidelines: 1. Introduction-GRADE evidence profiles and summary of findings tables. J Clin Epidemiol [Internet]. $2011 ; 64(4): 383-394$. Available from: http://www.ncbi.nlm.nih.gov/pubmed/21195583.

28. Guyatt GH, Oxman AD, Vist GE, Kunz R, Falck-Ytter Y, Alonso-Coello P, et al. GRADE: an emerging consensus on rating quality of evidence and strength of recommendations. BMJ [Internet]. 2008 ;336(7650):924-926. Available from: http://www.ncbi.nlm.nih.gov/pubmed/18436948.

29. Riley RD, Elia EG, Malin G, Hemming K, Price MP. Multivariate meta-analysis of prognostic factor studies with multiple cut-points and/or methods of measurement. Stat Med [Internet]. 2015 34(17):2481-2496. Available from: http://www.ncbi.n/m.nih.gov/pubmed/25924725.

30. Parmar MK, Torri $V$, Stewart L. Extracting summary statistics to perform meta-analyses of the published literature for survival endpoints. Stat Med [Internet]. 1998 ;17(24):2815-2834. Available from: http://www.ncbi.nlm.nih. gov/pubmed/9921604.

31. Symons MJ, Moore DT. Hazard rate ratio and prospective epidemiological studies. J Clin Epidemiol [Internet]. 2002;55(9):893-899. Available from: http://www.ncbi.nlm.nih.gov/pubmed/12393077.

32. Kunath F, Spek A, Jensen K, Zengerling F, Schmidt S. Prognostic factors for tumor recurrence in patients with clinical stage I seminoma undergoing surveillance--protocol for a systematic review. Syst Rev [Internet]. 2015:4:182. Available from: http://www.ncbi.nlm.nih.gov/pubmed/26684760.

33. Higgins J, Green S. Chapter 7: selecting studies and collecting data. Cochrane Handbook of Systematic Reviews of Interventions [Internet]. Version 5. Cochrane Collaboration, editor. 2011. Available from: www. cochrane-handbook.org.

34. Salgado R, Denkert C, Demaria S, Sirtaine N, Klauschen F, Pruneri G, et al The evaluation of tumor-infiltrating lymphocytes (TILS) in breast cancer: recommendations by an International TILs Working Group 2014. Ann Oncol Off J Eur Soc Med Oncol [Internet]. 2015 ;26(2):259-271. Available from: http://www.ncbi.nlm.nih.gov/pubmed/25214542.

35. Denkert C, Loibl S, Noske A, Roller M, Müller BM, Komor M, et al. Tumorassociated lymphocytes as an independent predictor of response to 
neoadjuvant chemotherapy in breast cancer. J Clin Oncol [Internet]. 2010; 28(1):105-113. Available from: http://www.ncbi.nlm.nih.gov/pubmed/1991 7869.

36. Ali HR, Provenzano E, Dawson S-J, Blows FM, Liu B, Shah M, et al. Association between CD8+ T-cell infiltration and breast cancer survival in 12,439 patients. Ann Oncol Off J Eur Soc Med Oncol [Internet]. 2014 ;25(8): 1536-1543. Available from: http://www.ncbinlm.nih.gov/pubmed/24915873.

37. Loi $S$, Michiels S, Salgado R, Sirtaine N, Jose V, Fumagalli D, et al. Tumor infiltrating lymphocytes are prognostic in triple negative breast cancer and predictive for trastuzumab benefit in early breast cancer: results from the FinHER trial. Ann Oncol Off J Eur Soc Med Oncol [Internet]. 2014;25(8):15441550. Available from: http://www.ncbi.nlm.nih.gov/pubmed/24608200.

38. Rody A, Holtrich U, Pusztai L, Liedtke C, Gaetje R, Ruckhaeberle E, et al. T-cell metagene predicts a favorable prognosis in estrogen receptor-negative and HER2-positive breast cancers. Breast Cancer Res. 2009:11(2):1-13.

39. Sabatier R, Finetti P, Mamessier E, Raynaud S, Cervera N, Lambaudie E, et al. Kinome expression profiling and prognosis of basal breast cancers. Mol Cancer [Internet]. 2011;10(1):86. Available from: http://www.molecularcancer.com/content/10/1/86.

40. Teschendorff AE, Miremadi A, Pinder SE, Ellis IO, Caldas C. An immune response gene expression module identifies a good prognosis subtype in estrogen receptor negative breast cancer. Genome Biol. 2007;(8):8, R157.

41. Ali HR, Chlon L, Pharoah PDP, Markowetz F, Caldas C. Patterns of immune infiltration in breast cancer and their clinical implications: a geneexpression-based retrospective study. PLoS Med [Internet]. 2016;13(12): e1002194. Available from: http://www.ncbi.nlm.nih.gov/pubmed/27959923.

42. Bense RD, Sotiriou C, Piccart-Gebhart MJ, Haanen JBAG, van Vugt MATM, de Vries EGE, et al. Relevance of tumor-infiltrating immune cell composition and functionality for disease outcome in breast cancer. J Natl Cancer Inst [Internet]. 2017;109(1). Available from: http://www.ncbi.nlm.nih.gov/ pubmed/27737921.

43. Bertucci F, Gonçalves A. Immunotherapy in breast cancer: the Emerging Role of PD-1 and PD-L1. Curr Oncol Rep [Internet]. 2017;19(10):64. Available from: http://www.ncbi.nlm.nih.gov/pubmed/28799073.

44. Dieci M V, Criscitiello C, Goubar A, Viale G, Conte P, Guarneri V, et al. Prognostic value of tumor-infiltrating lymphocytes on residual disease after primary chemotherapy for triple-negative breast cancer: a retrospective multicenter study. Ann Oncol Off J Eur Soc Med Oncol [Internet]. 2014 ;25(3):611-618. Available from: http://www.ncbi.nlm.nih.gov/pubmed/24401 929.

45. Bedognetti D, Maccalli C, Bader SBJ Al, Marincola FM, Seliger B. Checkpoint inhibitors and their application in breast cancer. Breast Care (Basel) [Internet]. 2016;11(2):108-115. Available from: http://www.ncbi.nlm.nih.gov/ pubmed/27239172.

46. Hartkopf AD, Taran F-A, Wallwiener M, Walter CB, Krämer B, Grischke E-M, et al. PD-1 and PD-L1 Immune checkpoint blockade to treat breast cancer Breast Care (Basel) [Internet]. $2016 ; 11(6): 385-390$. Available from: http:// www.ncbi.nlm.nih.gov/pubmed/28228704.

47. Zielinski C, Knapp S, Mascaux C, Hirsch F. Rationale for targeting the immune system through checkpoint molecule blockade in the treatment of non-small-cell lung cancer. Ann Oncol. 2013;24(5):1170-9.

48. Muenst S, Schaerli AR, Gao F, Däster S, Trella E, Droeser RA, et al. Expression of programmed death ligand 1 (PD-L1) is associated with poor prognosis in human breast cancer. Breast Cancer Res Treat. 2014;146(1):15-24.

49. Wang C, Zhu H, Zhou Y, Mao F, Lin Y, Pan B, et al. Prognostic value of PDL1 in breast cancer: A Meta-Analysis. Breast J. 2017;23(4):436-43.

\section{Publisher's Note}

Springer Nature remains neutral with regard to jurisdictional claims in published maps and institutional affiliations.

Ready to submit your research? Choose BMC and benefit from:

- fast, convenient online submission

- thorough peer review by experienced researchers in your field

- rapid publication on acceptance

- support for research data, including large and complex data types

- gold Open Access which fosters wider collaboration and increased citations

- maximum visibility for your research: over $100 \mathrm{M}$ website views per year

At BMC, research is always in progress.

Learn more biomedcentral.com/submissions 